* Corresponding author

Phone +421556022462

E-mail address: frantisek.trebuna@tuke.sk

(prof. multi. Dr.h.c. Ing. František Trebuňa, CSc.)

Article information

Article history: AMS-Volume16-No.2-00160-12

Received 15 January 2012

Accepted 15 May 2012

\section{Strain Fields Identification of Chosen Cycling Helmets Types by Their Impact Loading}

\author{
František Trebuňa* , Martin Hagara, Róbert Huňady
}

Department of Applied Mechanics and Mechatronics, Faculty of Mechanical Engineering, Letná 9, 04200 Košice, Slovak Republic

\section{BIOGRAPHICAL NOTES}

Dr.h.c. mult. prof. Ing. František Trebuňa, CSc. is a professor of applied mechanics, Head of the Department of Applied Mechanics and Mechatronics and Dean of the Faculty of Mechanical Engineering. He is author of 10 monographs, 12 university textbook, special book publications, 12 university notebooks and more than 300 publications in journals and conference proceedings at Slovakia abroad. He is author of important projects and engineering works. He received several prizes at home and abroad. He received three titles Doctor Honoris Causa (DHC) including two from foreign universities for the development of applied mechanics and mechatronics.

Ing. Martin Hagara after successful completion of his study at the Gymnasium of Pavol Orszagh Hviezdoslav in Kezmarok he has started studies at the Faculty of Mechanical Engineering of the Technical university of Kosice. He graduated a bachelor-degree study in Mechatronics in 2008. Thereafter he continued an engineer-degree study in Applied Mechanics. He defended his diploma thesis "Application of digital image correlation in solving problems of modal analysis" in 2010. Because of the results he has reached, he has been awarded the medal of excellent student by dean of the Faculty of mechanical engineering of the Technical university of Kosice. Nowadays he is a student of PhD-degree study in Applied mechanics, where he carries out research in methodics of digital image correlation in solving problems of mechanical structures dynamics.

Ing. Róbert Huňady, PhD. he received M.S. degree in mechanical engineering from Technical University of Košice, Slovakia in 2007. In 2009, he attended EC Marie Curie Training Program SIMVIA2 at Czech Technical University of Prague, Czech republic. He finished his doctoral study in study field Applied mechanics in Faculty of mechanical engineering at Technical University of Košice, Slovakia in 2010. Since 2010 he has been working as lecture at Department of Applied Mechanics and Mechatronics at Technical University of Košice, Slovakia. His professional activity is oriented into the area of modern optical methods of experimental mechanics such as high-speed digital image correlation, electronic speckle pattern interferometry and laser doppler vibrometry. He is author or co-author of more than 30 journals, conference papers and works aimed particularly at experimental modal and vibration analysis.

\section{KEY WORDS}

digital image correlation, drop test, cycling helmet

\section{ABSTRACT}

The use of a modern digital image correlation method to investigation of drop tests of two chosen cycling helmets types is described in this contribution. The first type 
- Arcore T-16 represents the helmets with more rounded uncomplicated surface and the second one - Longus Entry has flatter but more complicated contour. The investigation was directed to determination of helmets deformation and strain fields during their impact to a barrier. A high-speed system Q-450 Dantec Dynamics with cameras SpeedSense9070 Phantom was used to shoot this short time interval.

\section{Introduction}

Close attention to a human health-keeping is the main reason why cycling helmets should meet the strict safety requirements. Each continent, even some of states introduce some strict standards for helmet testing which have to be accomplished. For these standards (ANSI, ASTM, Australia/NZ, BSI, Canadian Standard Association, US Consumer Product Safety Commission, CEN European Standard, Japanese Industrial Standard, Snell Memorial Foundation, Swedish Board for Consumer Policies, ...) different types of tests, materials, models and aids used by testing are characteristic. The aim of experiments described in this contribution was perform a simple drop test of selected cycling helmets and evaluate deformation during their impact to a strong barrier. An application of conventional methods of experimental analysis of helmets deformation could be relatively complicated solution. Complexity of helmets structure and material do not allow using tensometric apparatus. On the other hand the time-consuming creation of model by applying of finite element methods is in this instance not very efficient and the model correspondence with reality may not be sufficient. The optical experimental methods are the answer for overcoming of these troubles. Unlike strain gauges used for deformation analysis in one place and its near locality, high-speed digital image correlation used in this contribution as evaluation apparatus purveys information about the whole sampled surface of investigated object.

\section{Digital Image Correlation (DIC)}

Digital image correlation is an optical method based on correlation principle of investigated object, which is shot by CCD cameras during its loading. The correlation process of acquired digital images, also called correlation, is performed gradually on small image elements called facets.
Shape of this elements use to be squared with usual size from $15 \times 15$ to $30 \times 30$ pixels. Stochastic black and white pattern is created on the object surface in order to correlation of identical parts of the images. There are various methods for creation of finer or coarser patterns (using of spray gun, easy coating of Xerox toner on wet white surface, manual painting by indelible ink felt pen or chemical etching of metal materials), but the easiest solution is a creation of pattern by white and black spray color.

Minimal size of facet is determined by size of created pattern. The every one facet has to contain white and black color in order to proper facets correlation.

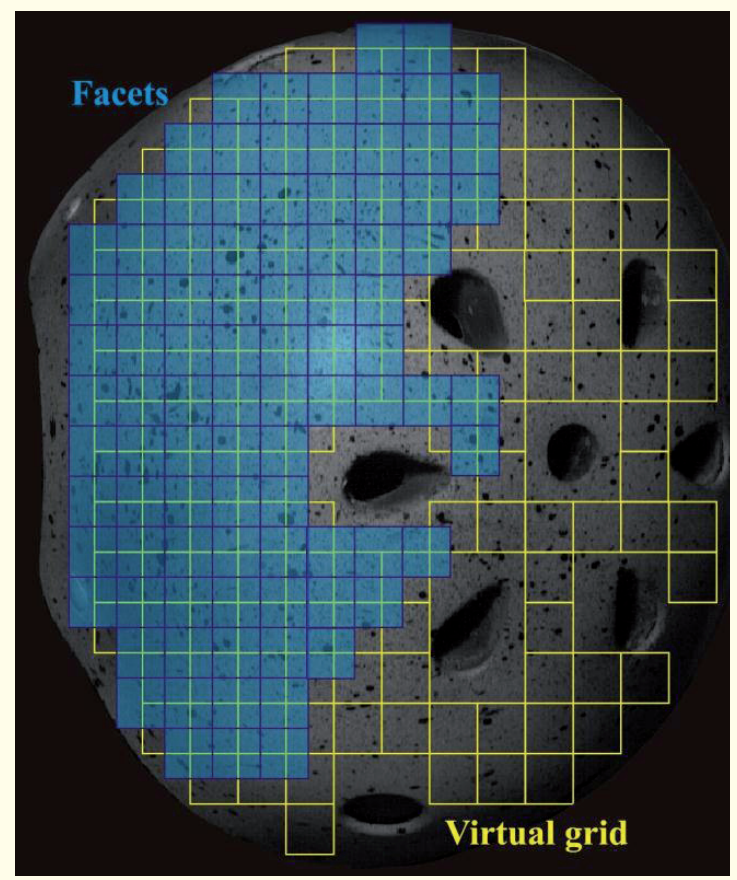

Fig. 1: Facets and virtual grid.

By digital image correlation method it is possible to determine displacement and strain fields. Values of displacements are determined in virtual grid corners created automatically by the software (Fig.1). Similarly, like by FEM programs where computation accuracy depends on size of finite element also the quality of results of digital image correlation depends on the size of virtual grid element. If the initial contour and displacement vectors of all element points are known, it is possible to com pute its strains. Acquisition of strains is ensured either by differentiation of adjoining point 
displacements or by analysis of local facets curving used by correlation [1], [2], [3].

Two CCD cameras are generally used by performing of experimental tests with using of highspeed correlation system Q-450 Dantec Dynamics. It is possible to investigate objects spatial deformations of size from several $\mathrm{mm} 2$ to some $\mathrm{m} 2$ by using of these cameras [4]. Such camera setting is conditioned by visibility of each investigated object point by both cameras simultaneously, what considerably complicate the investigation of objects with other than flat shape or objects with bigger surface rounding.

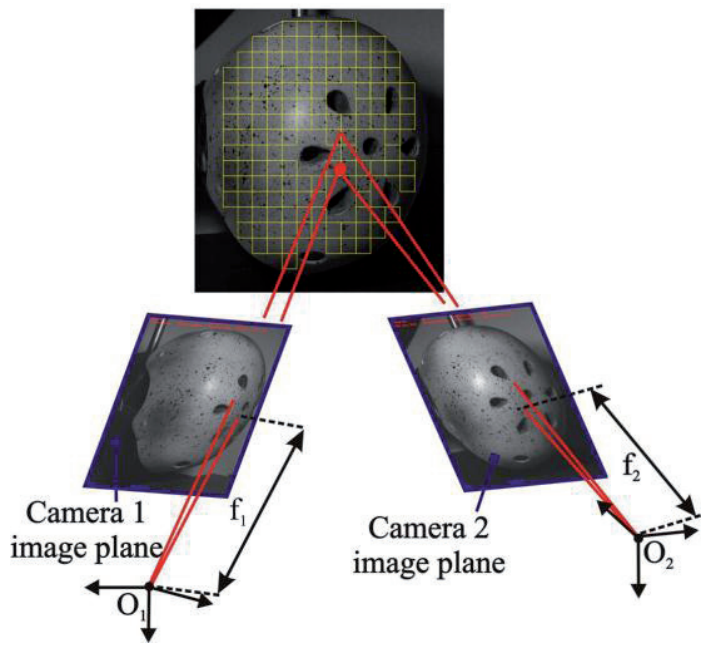

Fig. 2: Layout of stereoscopic setting of cameras.

If the investigation is performed by one camera then it is constrained only for planar objects situated parallel with camera image plane. For this instance it is not possible to perform spatial analysis but only planar one.

In general, camera can not distinguish the size and distance of sampled objects and therefore mini-sized object observed from small camera distance can appear as big as macroscopic one situated further. For this reason the acquisition of correct information about object deformation is dependent on process precision, also called calibration of cameras. Particular camera calibration process of optical system Q-450 Dantec Dynamics uses Zhang's algorithm [4], [5], [6].

\section{Experimental Determination of Cycling Hel- mets Deformation by Their Impact Testing}

The aim of the chosen experiments was to prove a convenience of 3-D digital image correlation by identification of cycling helmets deformation fields at a moment of their impact to a barrier in three mutually perpendicular directions $X, Y$ and $Z$. Two different types of cycling helmets were used for measurement - a freeride helmet Arcore T-16 represents the helmets with more rounded uncomplicated surface (Fig.3) and the second one - Longus Entry has flatter but more complicated contour (Fig.4).

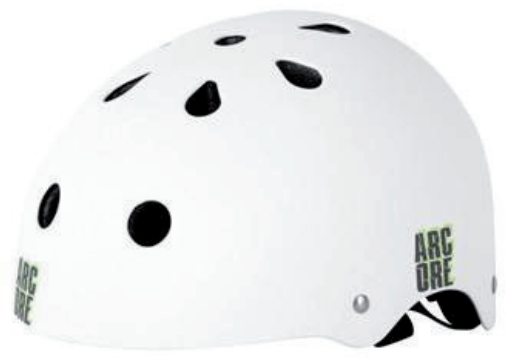

Fig. 3: Cycling helmet Arcore T-16.

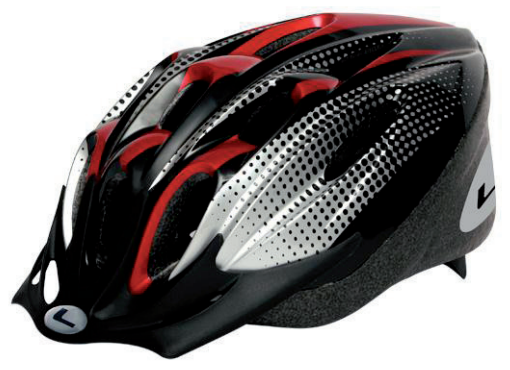

Fig. 4: Cycling helmet Longus Entry.

In accordance with the standard DRAFT ISO/DIS 6220-1983 a head model was made (Fig.5). This model of human head was made from hard oak wood and its weight with an attachment screw was above $3 \mathrm{~kg}$.

A construction for performing simple drop test was designed and manufactured as well. This structure consists of two fixed parts - a massive pedestal and a shifting conduction of length 2000 mm (Fig. 6). The choice of this length was performed in accord with Snell's assumption that most of cyclists fall down from a high above two meters.

For investigation of helmets deformation and strain resulting from their impact loading it is necessary to utilize a dynamic measurement with sufficiently high sampling frequency. AS the head impact speed was assumed above $6 \mathrm{~ms}^{-1}$ the sam- 
pling frequency of cameras was adjusted to the most viable value. The object illumination realized with one high-performance point source of white light and the character of CCD sensor chip allowed performing of dynamic measurements by sampling frequency of $6000 \mathrm{fps}$.

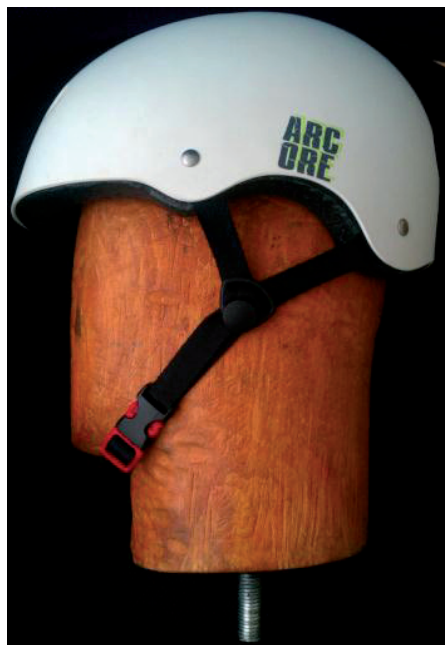

Fig. 5: Testing head model

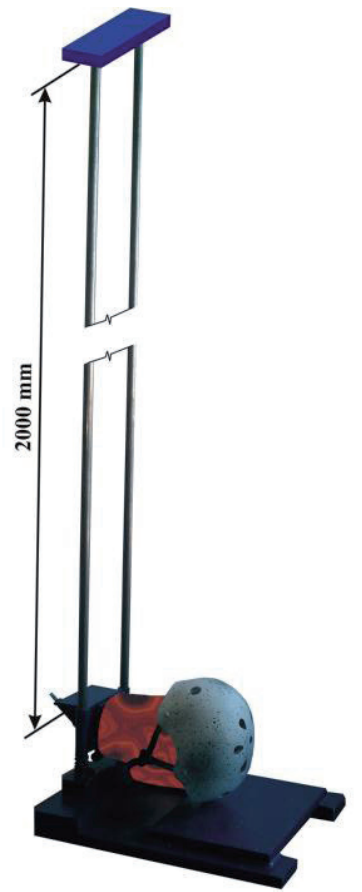

Fig. 6: Construction for performing simple drop test.

By using of spray color a random black and white contrary pattern was made on the helmets. Since the cameras resolution is only $1 \mathrm{MPx}$, the sprayed patches were of size from some micrometers to several millimeters to ensure their shooting by both cameras.

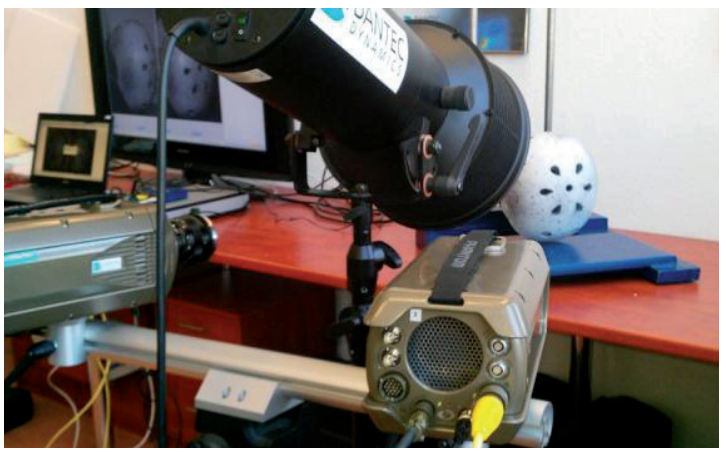

Fig. 7: Investigation of Arcore T-16 frontal impact to a flat part of the pedestal.

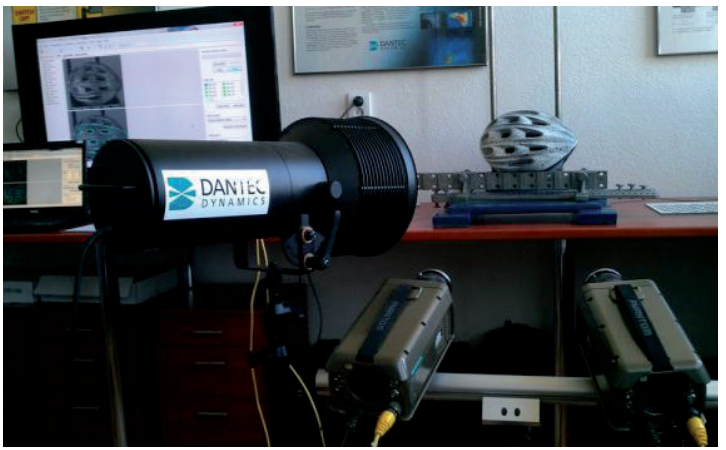

Fig. 8: Investigation of Longus Entry side impact to a sharp edge of the metal barrier.

The assignment of the investigated object movement in visual fields of both cameras and the visibility of each investigated object point from both cameras are two of the most important factors needed by using of high-speed correlation systems. The configuration with two cameras permitted shooting of frames from two different visual fields.

In regard to evaluation of the most viable part of helmets the main intention was utilize the helmets symmetry and shoot just their half. For this reason Arcore T-16 was by its frontal impact shot along side (Fig.7).

The same procedure was not possible to realize with Longus Entry comprised by a lot of complicated notches. These notches did not allow shooting of the identical surfaces by both cameras and the helmet reconstructed contour included a lot of non-evaluated parts. Because of this the second independent experiment was appointed - side impact of Longus Entry to a sharp edge of the metal 
barrier (Fig.8).

The apertures of both cameras were adjusted to 11 , the shutter times of them were set to maximal value $165,635 \mu$ s. These settings ensured sufficient image sharpness, optimal speed of lens and good contrast of investigated helmet parts.

The impact time was under ideal conditions and the acceleration of gravity equal to 9,81 m.s-2 determined by calculation above $0,64 \mathrm{~s}$. In accord to cameras internal memory of $16 \mathrm{~GB}$ the acquisition time was prescribed to 2,5s. Thus the whole process of helmet impact and potential rebound should be recorded with sufficient reserve. In both experiments 15000 snapshots were captured by each camera.

Subsequently the snapshots were stored and it was required to calibrate the system. Since the cameras locations and orientations were changed during experiments the calibration had to be performed for both measurements particularly.

In both cases the calibration target PL-23WMB_9x9 with square size of $23 \mathrm{~mm}$ was used. Fifteen images of its different locations and orientations were captured by both cameras and the calibration parameters were computed. The results of

Table 1: Calibration parameters obtained for experimental investigation of helmet Arcore T-16.

\begin{tabular}{|c|c|}
\hline \multicolumn{2}{|c|}{ Intrinsic Parameters Camera Position 1 image: } \\
\hline Focal length $\{x ; y\}$ : & $\{2736 \pm 2 ; 2739 \pm 2\}$ \\
\hline Principal point $\{x ; y\}$ : & $\{632 \pm 4 ; 476 \pm 6\}$ \\
\hline Radial distortion $\{r 2 ; r 4\}$ : & $\{-0,043 \pm 0,006 ;-0,24 \pm 0,08\}$ \\
\hline Tangential distortion $\{\mathrm{tx} ; \mathrm{ty}\}$ : & $\{0,0057 \pm 0,0005 ;-0,0023 \pm 0,0005\}$ \\
\hline \multicolumn{2}{|c|}{ Extrinsic parameters Camera Position 1 image: } \\
\hline Rotation vector $\{x ; y ; z\}$ : & $\{-2,950 \pm 0,002 ; 0,1211 \pm 0,0004 ;-0,157 \pm 0,002$ \\
\hline Translation vector $\{\mathbf{x} ; \mathbf{y} ; \mathbf{z}\}$ : & $\{65,5 \pm 1,4 ;-28 \pm 2 ; 919,8 \pm 0,7\}$ \\
\hline \multicolumn{2}{|c|}{ Intrinsic Parameters Camera Position 2 image: } \\
\hline Focal length $\{x ; y\}$ : & $\{2740 \pm 2 ; 2742 \pm 2\}$ \\
\hline Principal point $\{x ; y\}$ : & $\{636 \pm 5 ; 464 \pm 6\}$ \\
\hline Radial distortion $\{r 2 ; r 4\}$ : & $\{-0,093 \pm 0,007 ; 0,5 \pm 0,2\}$ \\
\hline Tangential distortion $\{\mathrm{tx} ; \mathrm{ty}\}$ & $\{0,0030 \pm 0,0005 ;-0,0004 \pm 0,0005\}$ \\
\hline \multicolumn{2}{|c|}{ Extrinsic parameters Camera Position 2 image: } \\
\hline Rotation vector $\{x ; y ; z\}$ : & $\{-2,938 \pm 0,002 ; 0,1711 \pm 0,0008 ; 0,509 \pm 0,002\}$ \\
\hline Translation vector $\{x ; y ; z\}$ : & $\{-10,1 \pm 1,5 ;-18 \pm 2 ; 914,5 \pm 0,7\}$ \\
\hline
\end{tabular}

Table 2: Calibration parameters obtained for experimental investigation of helmet Longus Entry.

\begin{tabular}{|c|c|}
\hline \multicolumn{2}{|c|}{ Intrinsic Parameters Camera Position 1 image: } \\
\hline Focal length $\{x ; y\}$ : & $\{2737 \pm 2 ; 2736 \pm 2\}$ \\
\hline Principal point $\{x ; y\}$ : & $\{681 \pm 5 ; 412 \pm 5\}$ \\
\hline Radial distortion $\{\mathrm{r} 2 ; \mathrm{r} 4\}$ : & $\{-0,071 \pm 0,007 ;-0,40 \pm 0,19\}$ \\
\hline Tangential distortion $\{\mathbf{t x} ; \mathbf{t y}\}$ : & $\{0,0016 \pm 0,0004 ; 0,0047 \pm 0,0005\}$ \\
\hline \multicolumn{2}{|c|}{ Extrinsic parameters Camera Position 1 image: } \\
\hline Rotation vector $\{x ; y ; z\}$ : & $\{2,7938 \pm 0,0018 ;-0,0547 \pm 0,0005 ; 0,175 \pm 0,0\}$ \\
\hline Translation vector $\{\mathbf{x} ; \mathbf{y} ; \mathbf{z}\}$ : & $\{-15,9 \pm 1,7 ; 44,6 \pm 1,7 ; 934,7 \pm 0,8\}$ \\
\hline \multicolumn{2}{|c|}{ Intrinsic Parameters Camera Position 2 image: } \\
\hline Focal length $\{x ; y\}$ : & $\{2759 \pm 2 ; 2755 \pm 3\}$ \\
\hline Principal point $\{x ; y\}$ : & $\{652 \pm 6 ; 395 \pm 6\}$ \\
\hline Radial distortion $\{r 2 ; \mathrm{r} 4\}$ : & $\{-0,092 \pm 0,006 ; 0,60 \pm 0,14\}$ \\
\hline Tangential distortion $\{\mathbf{t x} ; \mathbf{t y}\}$ : & $(-0,0015 \pm 0,0005 ; 0,0044 \pm 0,0007\}$ \\
\hline \multicolumn{2}{|c|}{ Extrinsic parameters Camera Position 2 image: } \\
\hline Rotation vector $\{x ; y ; z\}$ : & $\{2,771 \pm 0,002 ; 0,0169 \pm 0,0006 ;-0,281 \pm 0,003\}$ \\
\hline Translation vector $\{\mathbf{x} ; \mathbf{y} ; \mathbf{z}\}$ : & $\{-42 \pm 2 ; 58,1 \pm 1,9 ; 946,7 \pm 0,9\}$ \\
\hline
\end{tabular}

calibrations are introduced in Tab.1 and Tab.2.

After the inspection of stored snapshots, only these were chosen, which were related to the helmet impact to the barrier. Arcore T-16 rebounded from the pedestal four times and thus stopped. In regard to the highest awaited deformation by the first impact, only this part of record was evaluated. Longus Entry was just turned to the side and subsequently stopped after its impact to the metal barrier. The first snapshot from all correlated snapshots was determined as reference, the rest as sub-reference. This procedure made the searching of starting points (a place which is correlated as first) much easier.

In the next step an evaluation mask was created. This mask defines on the reference step a region, which should be evaluated (Fig. 9, Fig.10).

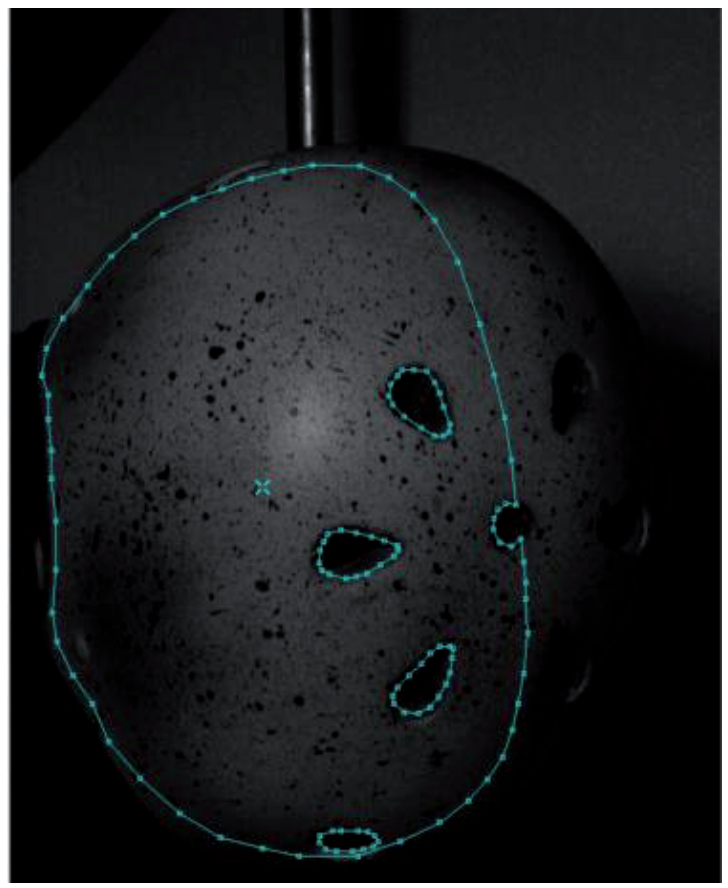

Fig. 9: Evaluation mask of Arcore T-16.

The visibility of all points of the investigated object on each evaluated snapshot obtained by both cameras is the primary factor of mask making. For each mask created by closed polygons it is necessary to set at least one starting point occurred in its inside. The place marked by starting point is correlated always as first.

The reconstructed three-dimensional contours of both helmets are depicted in the Fig.11 and Fig.12. 
The contour of Arcore T-16 was obtained with relatively good quality, Longus Entry with its more complicated shape showed worse quality of reconstruction. At least another one camera could be used to remove these imperfections.

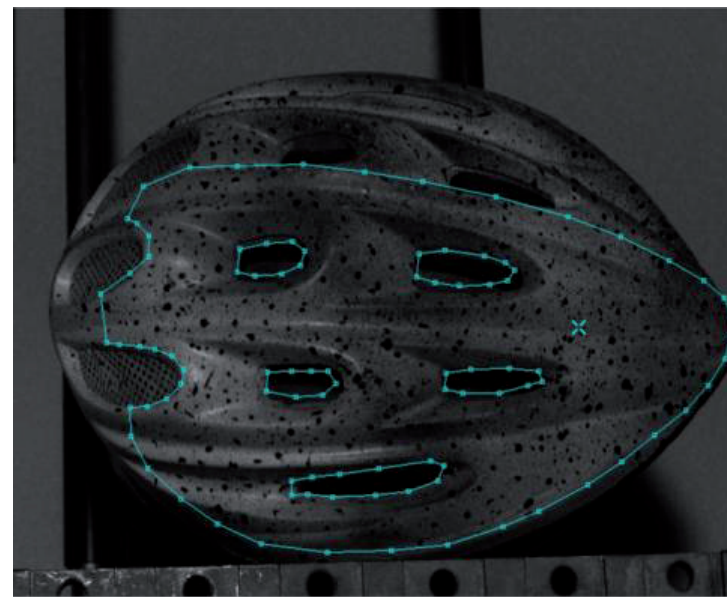

Fig. 10: Evaluation mask of Longus Entry.

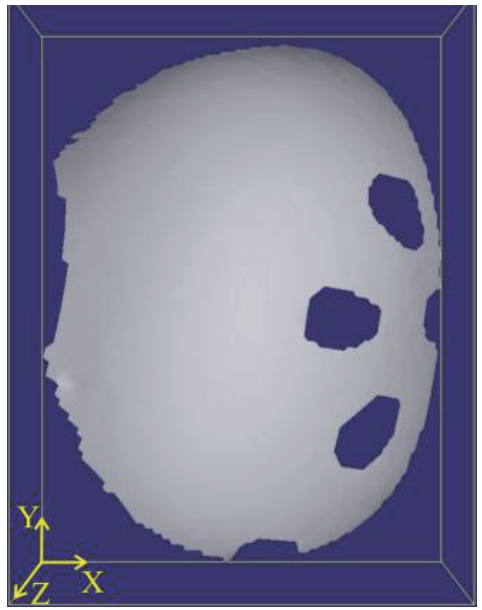

Fig. 11: Reconstructed three-dimensional contour of Arcore T-16.

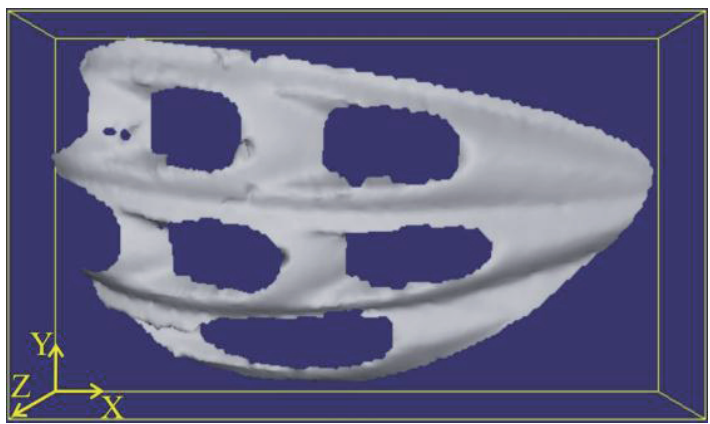

Fig. 12: Reconstructed three-dimensional contour of Longus Entry
The results in a form of principal strain, total deformations and deformations in $X, Y$ and $Z$ directions can be seen in the Fig. 13 and Fig. 14.

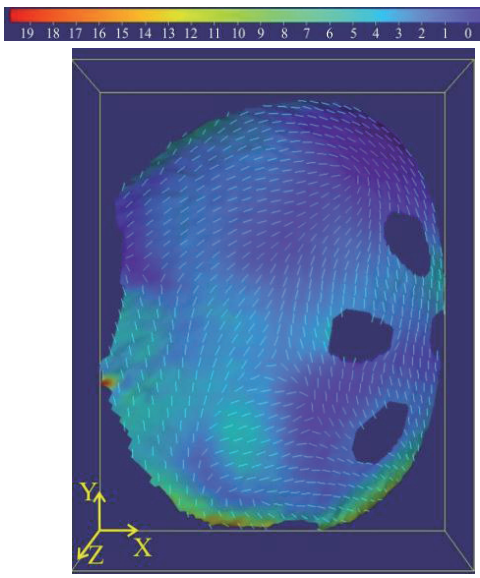

a) Principal strain $1^{*}$

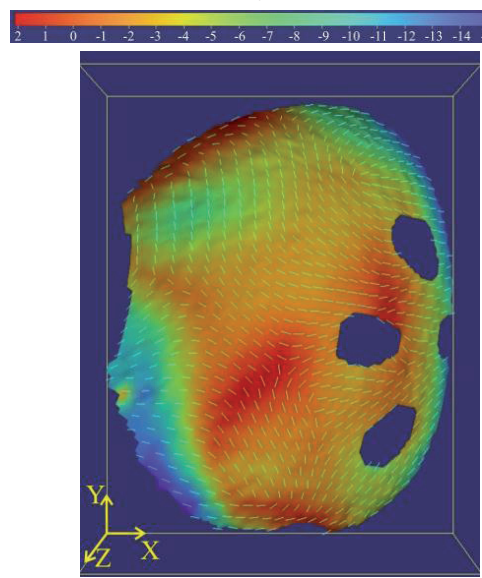

b) Principal strain 2

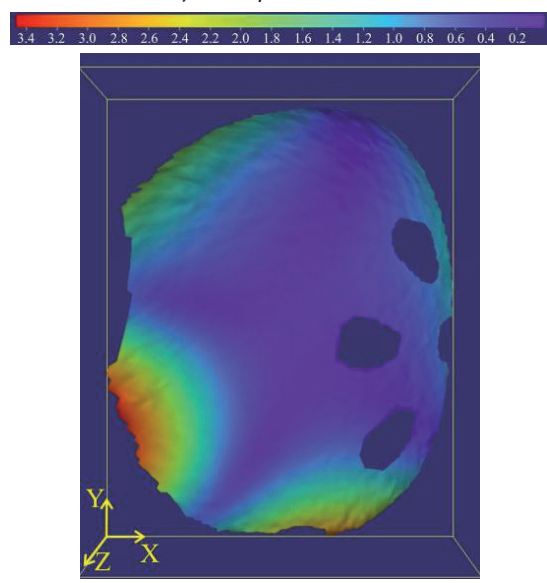

c) Total deformation

Fig. 13: Visualization of strain fields and deformations of tested helmet Arcore T-16 at its stop on the pedestal. 


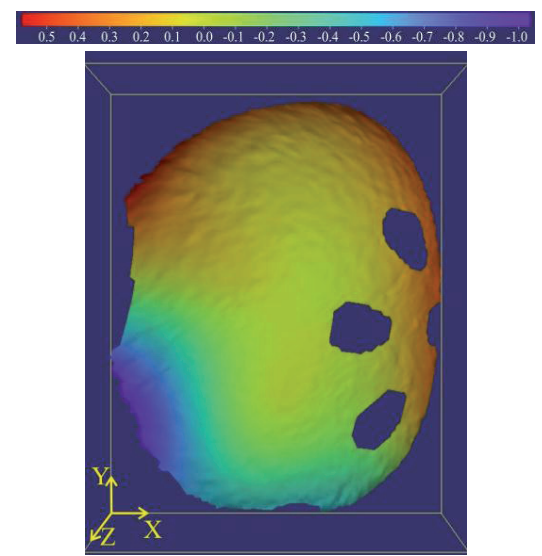

d) Deformation in $X$ direction

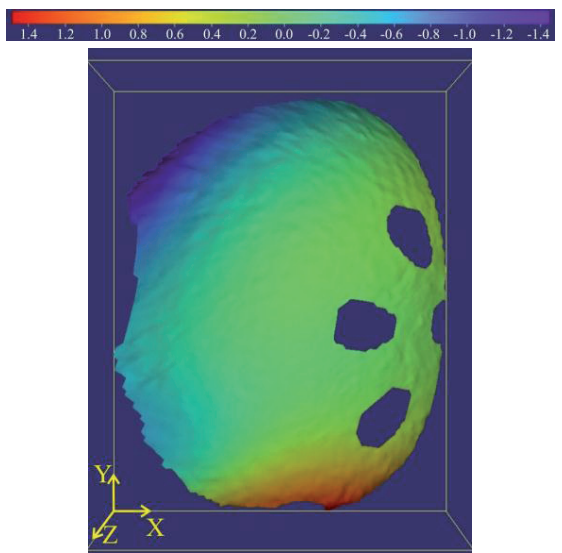

e) Deformation in $Y$ direction
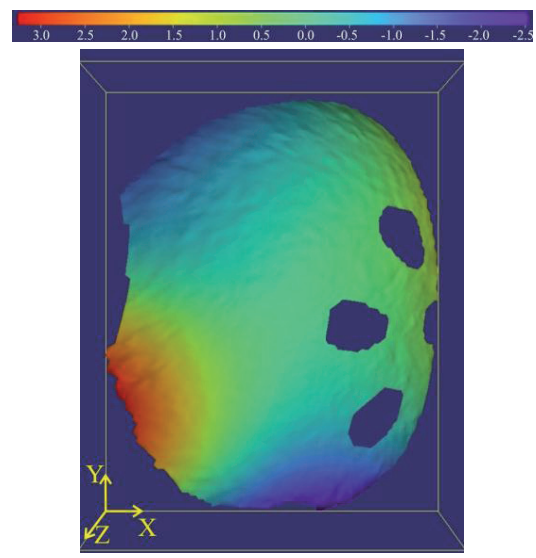

f) Deformation in $Z$ direction

Continuation of the Figure 13: Visualization of strain fields and deformations of tested helmet Arcore T-16 at its stop on the pedestal.

\section{Evaluation of obtained results}

The strain fields and deformations of investigated area are the result of experimental investigation of

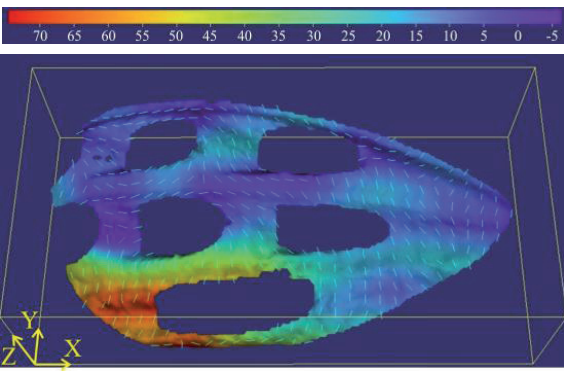

a) Principal strain $1^{*}$

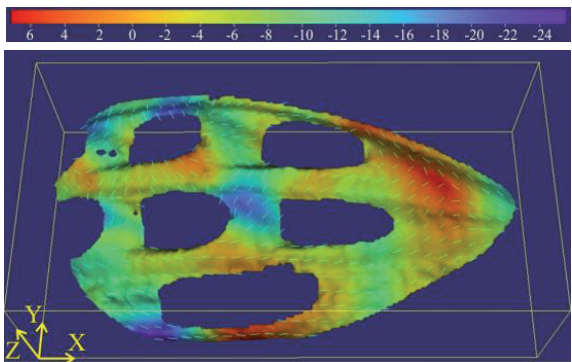

b) Principal strain $2^{*}$

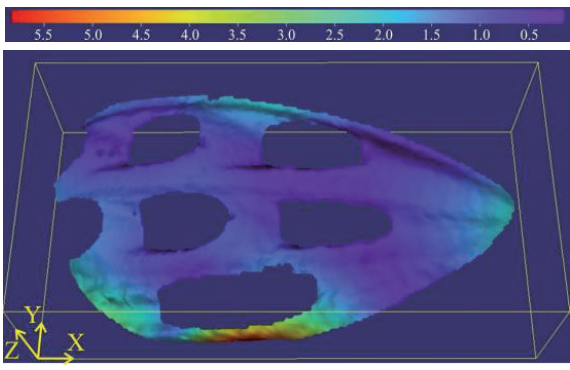

c) Total deformation

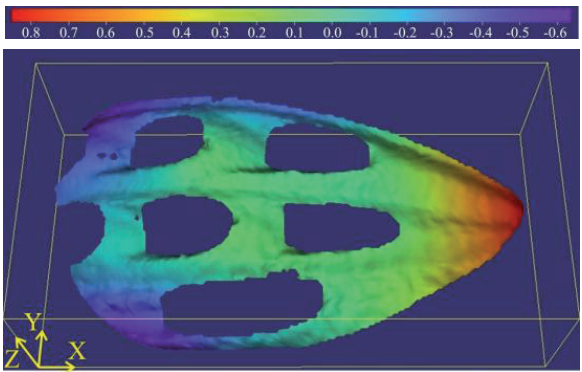

d) Deformation in $X$ direction

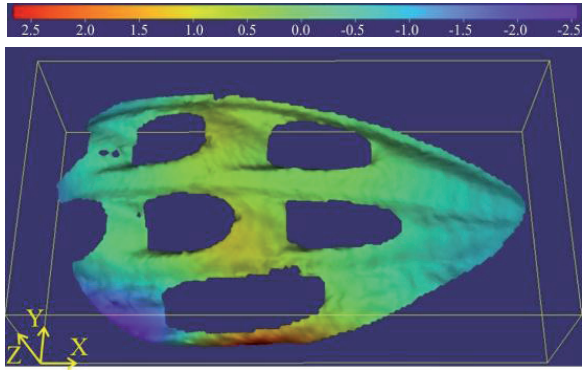

e) Deformation in $Y$ direction 


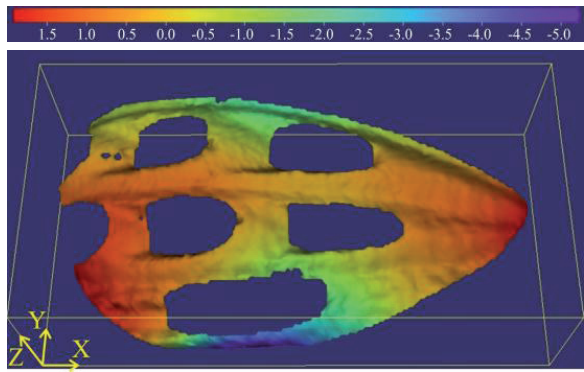

f) Deformation in Z direction

Fig. 14: Visualization of strain fields and deformations of tested helmet Longus Entry at its stop on the barrier

*Annotation: The principal strains directions 1 and 2 are in the Fig.13a, Fig.13b, Fig.14a and Fig.14.b depicted by white arrows covered the whole evaluated region.

bicycle helmet drop tests. By using of given set up of correlation system Q-450 with two cameras and one source of light the identical experiments could not be performed, which result would be the comparison of both types of helmets deformation. For this reason two independent experiments were chosen. The size of investigated area and quality of reconstructed image give an assumption to utilizing the digital image correlation method with stereoscopic set up of both cameras especially for objects with simpler contour. It is necessary to have three even four cameras for correct shooting and evaluating of entire helmet surface. During the impact of both helmets on barrier the mechanical damage has occurred (see Fig. 15 and Fig. 16). In both cases the damping stiffened polystyrene matter was cracked. In the case of helmet Arcore T-16 the smooth surface layer was in forehead area divided from polystyrene matter. During the impact of helmet Longus Entry on a sharp barrier the crack of shell has occurred.

Apparently the friction of construction parts has caused that by using of accelerometers the measured velocity of helmets closely to impact on barrier was $5,1 \mathrm{~ms}^{-1}$. The forty time steps have passed from the first contact of helmet Arcore T-16 with barrier up to the stopping of helmet on barrier. It means that the system caught particular number of snapshots during which the motion of helmet was stopped. By sampling frequency $6000 \mathrm{fps}$ the time interval lasts $0,00666 \mathrm{~s}$. Impact of the helmet on pedestal created overloading of size $78 \mathrm{~g}$. Such overloading is for human body during the longstanding exposure unacceptable though for short-time exposure (approximately 0,1s) human body can withstand overloading about 83g.

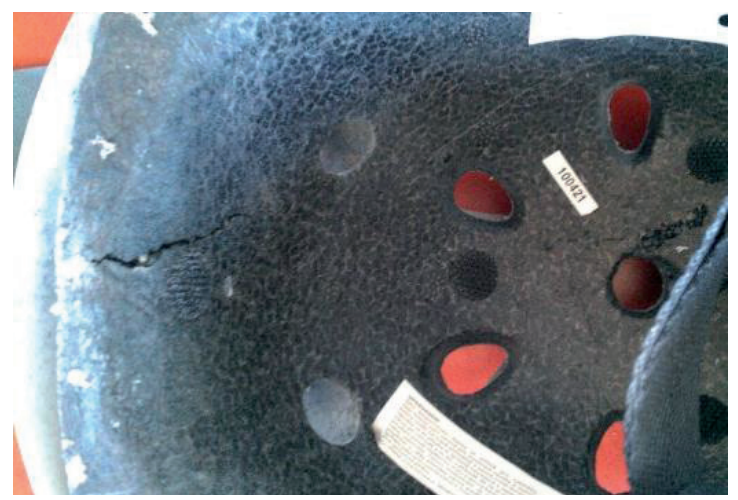

Fig. 15: Crack in polystyrene matter and division of shell from helmet Arcore T-16.

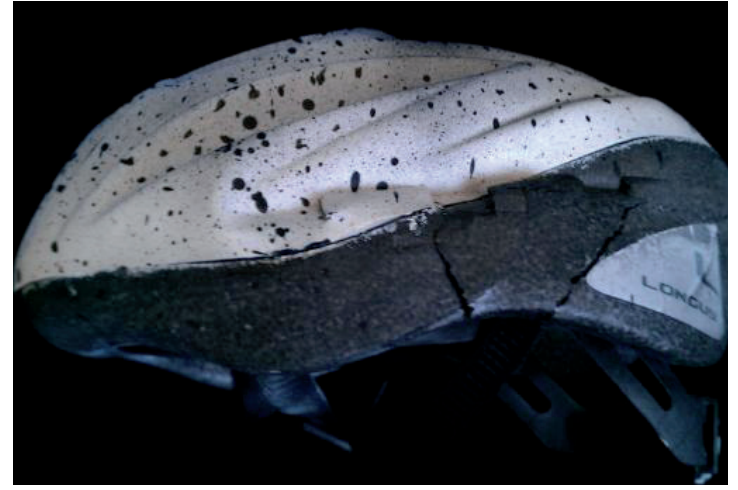

Fig. 16: Mechanical damage of helmet Longus Entry caused by its impact on a sharp barrier.

\section{Conclusion}

The aim of this contribution was to point out the possibility of experimental method application of image correlation by performing of cycling helmet drop tests. As one can see from described experiments it is possible to realize investigation of dynamic processes in broad range of cameras sampling frequencies with system Q-450 Dantec Dynamics. However a sensor chip of this device enables to perform measurement only to 3140fps by full resolution. The using of higher sampling frequencies is possible only for smaller objects. Increasing of sampling frequency tends to faster aperture objective closing and the demands for more qualitative specimen illumination increasing too. Then for measurement with higher sampling frequency of camera than 6000fps it is necessary one more high-performance source of light. Consideration 
of given helmet convenience for health protection and impact influence for human body would be possible only after performing of others measurements performed on helmets and consequent consultation with experts of given area. The primary aim of experiment was not to investigate security of helmets but show the possibility of digital image correlation utilization by such high-speed sampling of object impact loading.

\section{Acknowledge}

The authors would like to express their gratitude to Scientific Grant Agency VEGA MŠ SR for the support of this work under Project No. 1/0289/11 and No. 1/0937/12.

\section{References}

[1] SIEBERT T. et al.: New features in digital image correlation techniques. In 22nd DANUBIA-ADRIA Symposium on Experimental Methods in Solid Mechanics, Parma : MONTICELLI TERME, 2005.

[2] HUŇADY, R.: Možnosti využitia metódy digitálnej obrazovej korelácie v aplikáciách dynamiky. Dizertačná práca. Košice: Technická univerzita v Košiciach, Strojnícka fakulta, 2010.

[3] HAGARA, M.: Uplatnenie metód obrazovej korelácie $v$ dynamike mechanických sústav. Písomná práca k dizertačnej skúške. Košice: Technická univerzita v Košiciach, Strojnícka fakulta, 2012

[4] www.dantecdynamics.com

[5] TREBUŇA, F. et al.: An Application of High-speed Digital Image Correlation in Determination of Modal Parameters. In Acta Mechanica Slovaca, vol. 15, no. 4, 2011, ISSN 1335-2393

[6] TREBUŇA, F. - ŠIMČÁK, F.: Príručka experimentálnej mechaniky. Košice: Typopress, 2007, ISBN 970-80-8073-816-7 